S sciendo International Conference KNOWLEDGE-BASED ORGANIZATION
Vol. XXVII

\title{
THE ROLE OF LOBBYING IN THE DECISION-MAKING PROCESS IN THE EUROPEAN UNION
}

\author{
Veronika STOILOVA \\ "Neofit Rilski" South-West University, Blagoevgrad, Bulgaria \\ veronikabg@gmail.com
}

\begin{abstract}
Lobbying in the modern world is becoming part of decision-making processes at the local, state, supranational and global levels. The lobbying process is characterized by the use of various techniques and tools, which is why there are many definitions. In the European Union, it is perceived as a European representation of interests, through which different groups try to influence the decision-making process in the various institutions. Lobbying is often referred to when it is necessary to describe a particular political process, event or phenomenon that has not reached the general public or has remained opaque due to its specific nature. As lobbying becomes increasingly important, this article aims to clarify what lobbying is and what its legitimate and acceptable forms are. It is not without reason that there is a general distrust of the lobbying process and, in particular, of the real intentions of lobbyists. Therefore, many people believe that such activities distort the political process in terms of transparency, integrity and influence. Given the sensitive nature of the topic of lobbying, some good practices from existing lobbying rules at European level will also be considered.
\end{abstract}

\section{Keywords: lobbying, influence, transparency, European Union, EU legislation}

\section{Introduction}

Lobbying is not a process that the general public understands well. It is widely used as a concept, but few have a real idea of what exactly lobbyists do and why they do it. Lobbying in the modern world is becoming part of decision-making processes at the local, state, supranational and global levels. The lobbying process is characterized by the use of various techniques and tools, which is why there are many definitions. In the European Union, it is perceived as a European representation of interests, through which different groups try to influence the decision-making process in the various institutions. Lobbying is often referred to when it is necessary to describe a particular political process, event or phenomenon that has not reached the general public or has remained opaque due to its specific nature. As lobbying becomes increasingly important, this article aims to clarify what lobbying is and what its legitimate and acceptable forms are.

It is not without reason that there is a general distrust of the lobbying process and, in particular, of the real intentions of lobbyists. Therefore, many people believe that such activities distort the political process in terms of transparency, integrity and influence.

EU Member States apply different approaches to regulating the lobbying process by introducing legislative changes, codes of conduct for lobbyists, as well as mandatory registers for practitioners. The regulation of lobbying is a topic that has yet to engage the attention of the countries of the Union together and separately. In this sense, the activity that involves both 
lobbyists (and lobbying companies) and the institutions and individuals subject to lobbying should be carefully examined, taking into account its legal and political aspects. Given the sensitive nature of the topic of lobbying, some good practices from existing lobbying rules at European level will also be considered.

\section{Lobbying and the decision-making process}

As part of the political process, lobbying emerged in the 20th century with the establishment of modern democratic societies. However, its roots can be traced back to the second half of the 16th century, when the lobby, as an anteroom of the House of Commons of the English Parliament, was open to the public and used by people to meet and talk to members of the parliament. Some researchers attribute the concept of lobbying to the right to petition, which was confirmed by the first amendments to the US Constitution [1] in 1789, which are better known as the US Bill of Rights. Since then, the concept of lobbying has been officially used by Congress in its documents [2].

Since the first official lobbying law was passed in the United States in 1946 [3], the first attempt to regulate lobbying also took place at that time. In the context of this legal act, and subsequently with the attempts to find a basis for the legal regulation of the activity in the different countries of the world, the essence of this activity is formed - a legally regulated activity, which is expressed in regulated attempts for influence by certain groups, respectively individuals, on the managerial decision making process. The preconditions for the development of such activity in modern democratic societies are precisely the existence of democratic governance and guaranteed rule of law.

As part of the democratic process, civil society also falls under lobbying. What does this mean? It means that in order to achieve certain public interests, they need to be clearly identified not only by the institutions in a country, but also by civil society. It should therefore be mentioned that lobbying is directly linked to the practical implementation of democracy and, in particular, to the coherence between the interests of the state, on the one hand, and those of the various existing groups within civil society. In this sense, it should be noted that the most common dimensions of lobbying are for civic interests, common important values or business interests.

The defense of civic interests is directly related to the topic of political representation, which in its essence is carried out through the activities of political parties in the country or through that of various civic organizations and pressure groups. The main goal here is to protect certain group interests.

Due to the fact that political representation is increasingly losing its trust, civil and business interest organizations (such as different trade unions, non-governmental organizations, employers' organizations, business associations, creative unions, etc.) are gaining more popularity in the attempt to protect their interests in the managerial decision making process.

Thus, lobbying should be seen as a mechanism for interest representation, through which different groups try to influence the decision-making process in the different institutions. This is also the understanding of lobbying in the European Union described in the Green Paper on the European Transparency Initiative [4], adopted in 2006.

The political decision-making process is characterized by increasing dynamics and complexity. This, in turn, necessitates the search for qualified experts to engage in professional lobbying. The latter is strongly relevant to lobbying in the EU. In this sense, it should be summarized that if such activity is not controlled in the manner prescribed by the state concerned, including by civil society itself, there is a considerable danger that this same lobbying 
process will overstep the legal framework and take the form of a crime. Therefore, the procedure for access to the decision-making process must be clearly defined so as not to distort the political process in terms of transparency, integrity and influence.

\section{Legal framework}

The last 20 years have been successful for the development of the lobbying process within the EU institutions. The reason for this could be found in the deepening of integration processes and the development of Community law (acquis communautaire), whose achievements cover more and more new areas that need to be regulated at the supranational level.

As a kind of "sui generis" political organization, the EU monitors the observance of the principles of democracy and the rule of law by the Member States. As a result, the Union sees lobbying as an important part of the European legislative process [5]. At present, however, there is no single legal framework for lobbying in the EU. What could be perceived as a basis for the adoption of appropriate legislation are the acts of secondary legislation, which in one form or another are related to lobbying. In this context, it should be mentioned that for the first time in 1996, the European Parliament regulated the access of interest groups to its building by providing a special pass system, which introduced transparency about the activities of individual organizations, and they were obliged to comply with a code of conduct with certain ethical standards.

In 2001, the Commission adopted the White Paper on Good Governance [6], which became popular with the introduction of the five principles of good governance (openness, participation, accountability, efficiency, and consistency) and the identification of the need to modernize the political process. Lobbying is relevant in the context of openness and participation in EU decision-making process. This also outlines the role of lobbyists in the
European legal order - lawmaking should identify problems and know the needs of societies in the Member States in order to make the decisions taken in the form of legislation adequate and operational, on the one hand, and civil society organizations should share their concerns and problems so that they can contribute to a more sustainable and realistic legislative process, on the other hand.

In addition to the White Paper on Good Governance, the European Commission adopted in 2002 a Communication on a strengthened culture for dialogue and consultation [7], which aims to improve consultation procedures by creating a transparent and coherent framework by setting minimum standards for consultation. However, these standards are legally binding on interest groups and not on the Commission.

The next step towards legal regulation of lobbying is the signing of an Interinstitutional Agreement in 2003 by the European Parliament, the Council, and the Commission with a focus on ensuring better lawmaking [8]. The significance of this document lies in the fact that in addition to reaffirming the principles of subsidiarity and proportionality, it also encourages the use of alternative methods of regulation, namely self-regulation and co-regulation. In addition, the document states that prelegislative consultation, impact assessment, and consistency of texts are the three methods to improve the quality of legislation. It is therefore important to note that communication is a key prerequisite for creating realistically applicable and effective policies.

Subsequently, in 2005 the Commission adopted an additional document, the Green Paper on the European Transparency Initiative [9], which aims to emphasize the need for transparency in the legislative process. In this sense, it should be summarized that the follow-up given to this document is a testament to its enduring nature and the ambition to bring more 
clarity to EU decision-making and increase public confidence in its institutions.

Subsequent initiatives to regulate the lobbying process are linked to other transparency initiatives - the creation of the first voluntary register of lobbyists in 2008 . The European Commission Register of Interest Representatives [10] introduces a mandatory code of conduct, which could be defined as a kind of framework to regulate relations between the EU institutions and representatives of interest groups.

Other regulatory attempts made at the level of the European Union institutions are the interinstitutional agreements signed in 2011 and 2014, with which Parliament and the Commission set up a joint voluntary transparency register [11] and improved the rules on financial disclosure and data availability [12]. In addition, the Commission requires the publication of information in connection with meetings held by Commissioners, members of their cabinets, and the Directors-General of the institution with organizations and selfemployed individuals.

Similar are the actions taken by Parliament at the institutional level in 2019 with the introduction of changes to the Rules of Procedure on the transparency of meetings held in Parliament's lobby [13].

From what has been said so far, it should be concluded that with regard to the institutional structure of the EU, each institution retains its autonomy and takes care of its internal rules and management of decision-making processes in a clear and transparent manner. In this sense, it is important to clarify that although the above-mentioned acts of secondary EU legislation have a direct impact on the behavior of lobbyists and those who are lobbied, the rules they create are not legally binding. However, it cannot be denied that there is a clear tendency to strengthen regulatory mechanisms at EU level in order to reform this matter.

\section{Lobbying or diplomacy?}

Characteristics of the lobbying activity are the clearly identified end goals and the target group to which the efforts for influencing the decision-making are directed. Unlike the United States, where lobbying has a positive meaning due to its established tradition and legal regulations, in Europe, this type of activity is still criticized for its association with the development of uncontrolled political manipulation and detrimental effects on the democratic functioning of the EU [14]. On the other hand, few Member States have legislation in place to regulate lobbying as an activity. That is why there is currently a tendency to use the term "legal representation" or "representation of interests" instead of lobbying.

There are often cases when lobbying is confused with the activities typical of multilateral diplomacy. This is due to the fact that both types of activity are aimed at defending certain interests and creating a dialogue in the decision-making process at the national, supranational, regional or international levels. What they have in common is the processes of persuasion and influence. They differ in the actors that implement them, namely the states through their participation in international relations, on the one hand, and interest groups, through their commitments to the policymaking process, on the other.

Although diplomacy is entirely relevant to the foreign policy of states, there are many examples of the fact that the differences between lobbying and diplomacy are not always clear. And it is the EU that is where diplomats and lobbyists most actively intersect.

Often, promoting an idea in the EU goes through lobbying, promoting and accepting it within the Member States, which is where the initiative to regulate a certain area of public relations comes from. Countries are active in diplomacy, defending their interests within the EU [15], but also engaging companies for professional 
lobbying to promote their foreign policy goals and influence the formation of the common EU policies. And this is quite logical, given the fact that about $80 \%$ of the national legislation of the Member States is influenced by EU law.

\section{Conclusions}

In conclusion, it should be summarized that lobbying can be analyzed from different perspectives, as it is considered not only an activity related to influencing decisionmaking but also as a policy area. Since the creation of the EU, lobbying has been active in the law-making process. The legal regulation of lobbying, therefore, proves to be a challenge, precisely because of the different legal frameworks existing in each Member State of the Union. Nevertheless, the review made in this article on the role of lobbying in the EU decision-making process reveals existing practices in the Union's activities that will serve as a good basis for the development of the matter.

In the European Union, lobbying definitely needs clear and transparent regulation, as the EU Member States apply different approaches to regulating the lobbying process by introducing legislative changes, codes of conduct for lobbyists, as well as mandatory registers for those practicing this kind of activity. The regulation of lobbying is a topic that has yet to engage the attention of the countries of the Union together and separately. In this sense, the activity that involves both lobbyists (and lobbying companies) and the institutions and individuals subject to lobbying should be carefully examined, taking into account its legal and political aspects.

\section{References List}

[1] USA Constitution. Available from: https://www.archives.gov/foundingdocs/constitution-transcript

[2] Bodenhamer, D. J., James W. Ely (Jr.), J. W., The Bill of Rights in Modern America, 2008 , pp. 7 - 25.

[3] USA. Lobbyist Regulation Act 1946. Available from: http://www.sos.state.nm.us/pdf/lra2.pdf

[4] Green Paper of 3 May 2006 - European transparency initiative [COM(2006) 194 final Official Journal C 151 of 29.6.2006].

[5] European Parliament, 'Lobbying in the European Union: current rules and practices' (Constitutional Affairs: Working Paper 2003).

[6] European governance - A white paper /* COM/2001/0428 final */ OJ C 287, 12.10.2001, pp. 1-29.

[7] Communication from the Commission - Towards a reinforced culture of consultation and dialogue - General principles and minimum standards for consultation of interested parties by the Commission $/ * \mathrm{COM} / 2002 / 0704$ final*/. Available from: https://eurlex.europa.eu/legal-content/EN/TXT/?uri=celex\%3A52002DC0704

[8] Interinstitutional agreement on better law-making OJ C 321, 31.12.2003, pp. 1-5.

[9] Green Paper - European transparency initiative /* COM/2006/0194 final */. Available from: https://eur-lex.europa.eu/legal-content/en/TXT/?uri=CELEX:52006DC0194.

[10] The European Commission Register of Interest Representatives. Available from: https://ec.europa.eu/transparencyregister/public/consultation/search.do?locale=en\&reset=

[11] Agreement between the European Parliament and the European Commission on the establishment of a transparency register for organisations and self-employed individuals engaged in EU policy-making and policy implementation OJ L 191, 22.7.2011, pp. 29-38. 
[12] Agreement between the European Parliament and the European Commission on the transparency register for organisations and self-employed individuals engaged in EU policy-making and policy implementation OJ L 277, 19.9.2014, pp. 11-24.

[13] Rules of Procedure of the European Parliament. Available from: https://www.europarl.europa.eu/doceo/document/RULES-8-2019-03-25-RULE-0111_EN.html

[14] Schendelen, R., More Machiavelli in Brussels. The Art of Lobbying the EU. Third, fully updated and revised edition, 2010, p. 319.

[15] Dimitrov, D. (2021), EU Citizenship Law: Integration of Immigrants, EURINT Proceedings, volume 7, pp. $50-62$. 